\title{
State of play and innovations in off-grid refrigeration technology: lessons learned from current initiatives
}

\author{
Nyamolo Abagi • Yasemin Erboy Ruff • \\ Jennifer Corry Smith • Michael Spiak
}

Received: 17 July 2018 / Accepted: 3 March 2019/Published online: 13 April 2019

(C) The Author(s) 2019

\begin{abstract}
Energy efficiency enables distributed off-grid renewable energy systems - from solar home systems to renewable micro-grids - to deliver energy services that otherwise might be economically or technically infeasible in resource-constrained settings. When superefficient appliances are used, the total cost of solar home systems and their associated appliances can be reduced by as much as 50\% (Phadke et al. 2015). The authors of this paper will first explore the broader interplay of energy access and energy efficiency for off- and weakgrid settings by sharing learnings from the Efficiency for Access Coalition and the UK aid funded Low-Energy Inclusive Appliances (LEIA) program. To serve as a concrete example among off-grid appliance technologies, this paper will then explore the work of LEIA and other Coalition partners to accelerate cost and efficiency improvements in off-grid refrigeration. Refrigeration presents significant technical challenges to off-grid energy systems because of high-energy demand in
\end{abstract}

N. Abagi

CLASP, Pine Tree Plaza, Kamburu Rd., Nairobi, Kenya

e-mail: nabagi@clasp.ngo

Y. Erboy Ruff • J. C. Smith $(\bowtie) \cdot$ M. Spiak

CLASP, 1401 K St. NW, Washington, DC 20005, USA

e-mail: jcorry@clasp.ngo

\author{
Y. Erboy Ruff \\ e-mail: yerboyruff@clasp.ngo \\ M. Spiak \\ e-mail: mspiak@clasp.ngo
}

addition to the lack of consistent and comparable performance data to help market stakeholders make effective and informed decisions about product selection. To help address this knowledge gap in the market, this paper presents the findings of a baseline product testing effort used to establish a foundational understanding of the field performance of commercially available off-grid refrigerators. The paper further explores the role of innovation cash prizes in catalyzing technology innovation and market expansion of off-grid refrigeration analyzing them through the lens of the Global Lighting and Energy Access Partnership (Global LEAP) Off-Grid Refrigerator Competition.

Keywords Refrigeration · Field monitoring · Innovation $\cdot$ Consumer research · Off-grid

\section{Introduction}

Background

Around 1.1 billion of the world's poorest people live entirely without access to electricity, another billion have only weak and unreliable access to the grid. Energy poverty depresses and delays social and economic development (Hirmer and Guthrie 2017). Increasingly, distributed clean energy technologies such as solar home systems (SHSs) and mini-grids are making it possible for people and businesses to access lifechanging modern energy for the first time. 


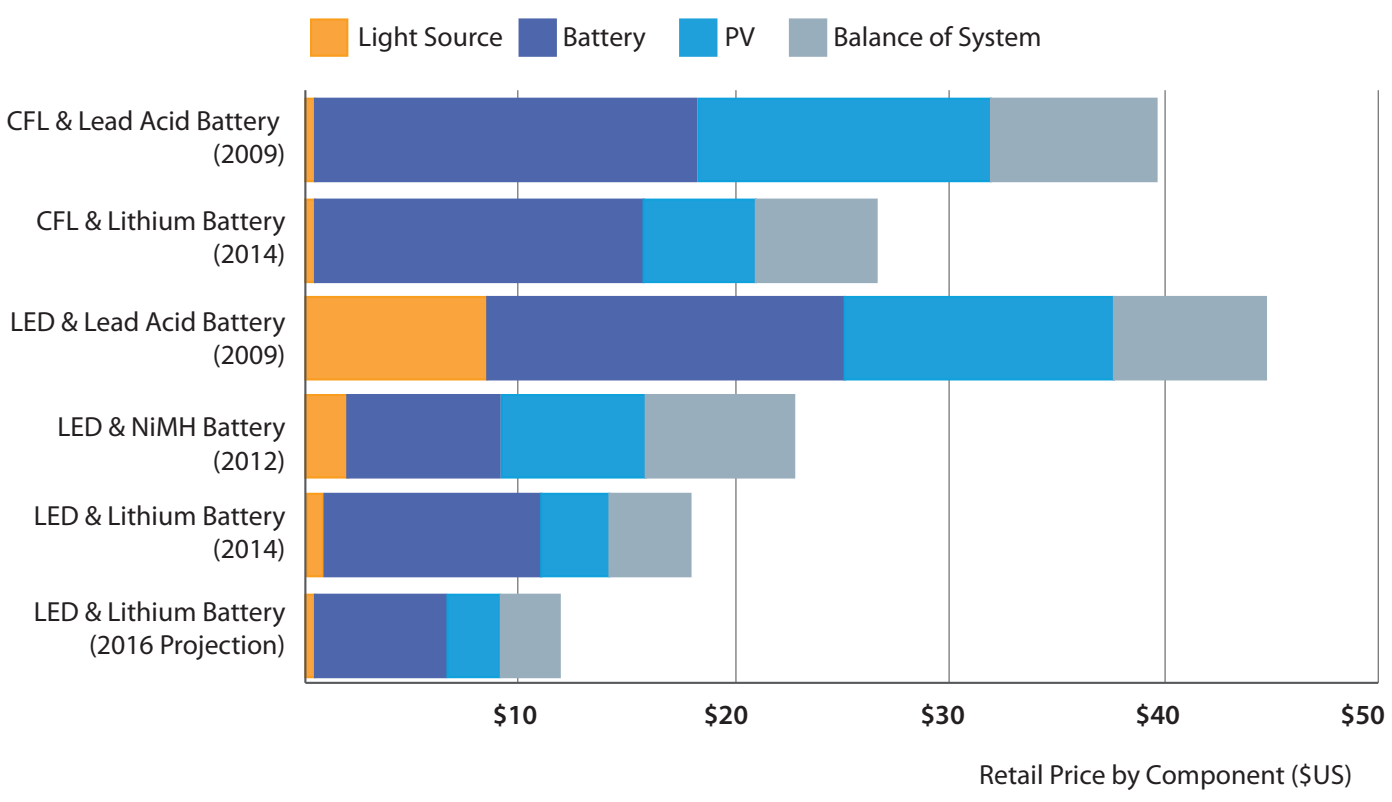

Fig. 1 Costs of a medium-sized Pico-PV lantern (Phadke et al. 2015)

While grid enhancement and extension will play an important role in achieving universal access to energy, the International Energy Agency has estimated that offgrid SHSs and mini-grids are the most economical way to reach around $70 \%$ of those in rural areas that are still not connected to the grid (International Energy Agency 2017).

Super-efficient light emitting diode (LED) technology, integrated into products and services designed for lowincome consumers, has played a dominant role in the development of this market. The price of off-grid solar lighting systems has dropped by $27 \%$ over the last 5 years (Off-Grid Solar Market Trends Report 2018), and the majority of the reduction is attributable to reduced solar panel costs. However, only around one-third of the reduction is due to reduced costs of the solar photovoltaic technology itself. The rest is due to the fact that energy efficient LEDs require smaller solar modules (and batteries) to provide the same service (Phadke et al. 2015). This is illustrated with real cost data (in US dollars) in Fig. 1. ${ }^{1}$

As promising as these new technologies are, the market penetration and level of investment seen in the household solar market are currently insufficient to deliver on the ambition of Sustainable Development Goal 7 to ensure access to affordable, reliable, sustainable, and modern energy for all by 2030 (World Bank 2018). Furthermore, the energy services offered at costs

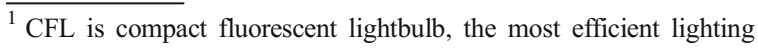
technology prior to the widespread availability of LEDs.
}

affordable to poor consumers are typically only lighting, mobile phone charging, and radios. The development impacts of these products are important but limited.

The continued development of this market-and continued progress in energy access - is tied to improved availability of appropriately designed, affordable, highly energy-efficient appliances. It is appliances that create and sustain demand for energy and deliver services like refrigeration, cooling, communications, and productivity that improve the lives and incomes of under-served households and communities.

However, conventional appliances frequently draw too much energy to be useful and/or economical when combined with off-grid energy systems and are typically poorly designed for such systems. Further, the combined energy demand of inefficient appliances often overloads weak electrical systems, contributing to load shedding and power outages, and undermining the gains of energy supply investment and grid extension.

Energy efficiency enables distributed off-grid renewable energy systems - from solar home systems to micro and mini-grids - to deliver energy services that otherwise might be economically or technically infeasible in resource-constrained settings. When super-efficient appliances are used, the total cost of solar home systems and their associated appliances can be reduced by as much as 50\% (Fig. 2) (Phadke et al. 2015). Improvements in the efficiency and prices of off-grid appropriate televisions (TVs), fans, and refrigerators are expected to 
Solar Home System (SHS) Purchase Price Based on Appliance Type

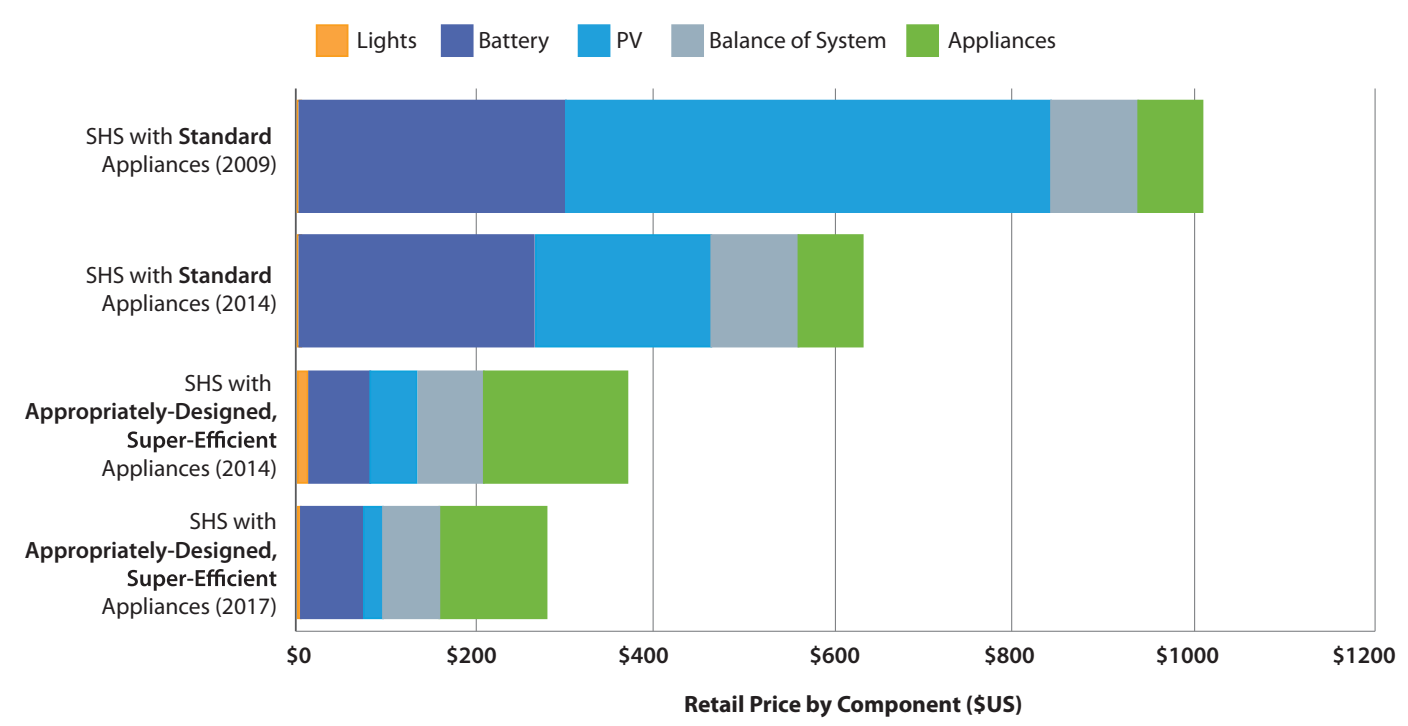

Fig. 2 Photovoltaic (PV) SHS costs for same level of service with different appliance packages (Phadke et al. 2015)

grow. A recent study forecasted that their combined global market potential to $\$ 4.7$ billion/year in 2020 , a ninefold increase in total market value, despite lower appliance prices (Fig. 3) (Global LEAP 2016). However, it should be noted that very little data is available on sales of appliances in off-grid markets and more data is needed to improve the accuracy of sales forecasts.

Just as super-efficient LED technology has unlocked the benefits of modern lighting for millions around the globe, other appliances promise cooling, communications, mechanization, and refrigeration to millions more, with improved outcomes for health, education, and productivity and livelihoods. Replicating this step-change in energy efficiency in other appliance segments would improve the impact and viability of solar home systems and minigrids, while reducing load and blackouts on weak grids.

For energy efficiency to deliver on its potential to enable greater energy access, much more data and information is needed on how products perform - both in the field and in the lab. To date, very little field testing has been done to understand how products perform across varying geographies and use cases. ${ }^{2}$ One of the pioneering field evaluation projects for off-grid refrigerators - implemented by the Global Lighting and Energy Access Partnership (Global LEAP)—will be described later in this paper.

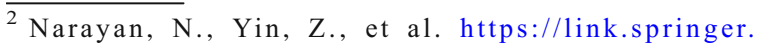
com/content/pdf/10.1007\%2Fs12053-018-9725-6.pdf
}

Moving from theory to practice - the Efficiency for Access Coalition

As discussed above, the off- and weak-grid appliance market remains nascent and under-resourced, with a continued need for market intelligence and partnership opportunities to scale sustainably. As a component of this sectorwide effort, Efficiency for Access first launched in 2015 as a year-long call to action with the aim to help move the sector towards resolving some of the challenges related to the off- and weak-grid appliance markets. In order to improve overall coordination and co-funding strategies, Efficiency for Access ${ }^{3}$ was then scaled up and reintroduced in January 2018 as a coalition promoting energy efficiency as a potent catalyst in global clean energy access efforts, jointly coordinated by CLASP ${ }^{4}$ and Energy Saving Trust (EST). ${ }^{5}$ Currently, UK Aid, ${ }^{6}$ USAID's Power Africa, ${ }^{7}$ the International Finance Corporation (IFC), ${ }^{8}$ the World Bank Group, ${ }^{9}$ Rockefeller Foundation, ${ }^{10}$ Shell

\footnotetext{
${ }^{3}$ Efficiency for Access: www.efficiencyforaccess.org

${ }^{4}$ CLASP: www.clasp.ngo

${ }^{5}$ Energy Saving Trust: www.energysavingtrust.org.uk

${ }^{6}$ UK Aid: www.ukaiddirect.org/

${ }^{7}$ Power Africa: www.usaid.gov/powerafrica

${ }^{8}$ International Finance Corporation: www.ifc.org

${ }^{9}$ World Bank Group: www.worldbank.org/

${ }^{10}$ Rockefeller Foundation: www.rockefellerfoundation.org/
} 


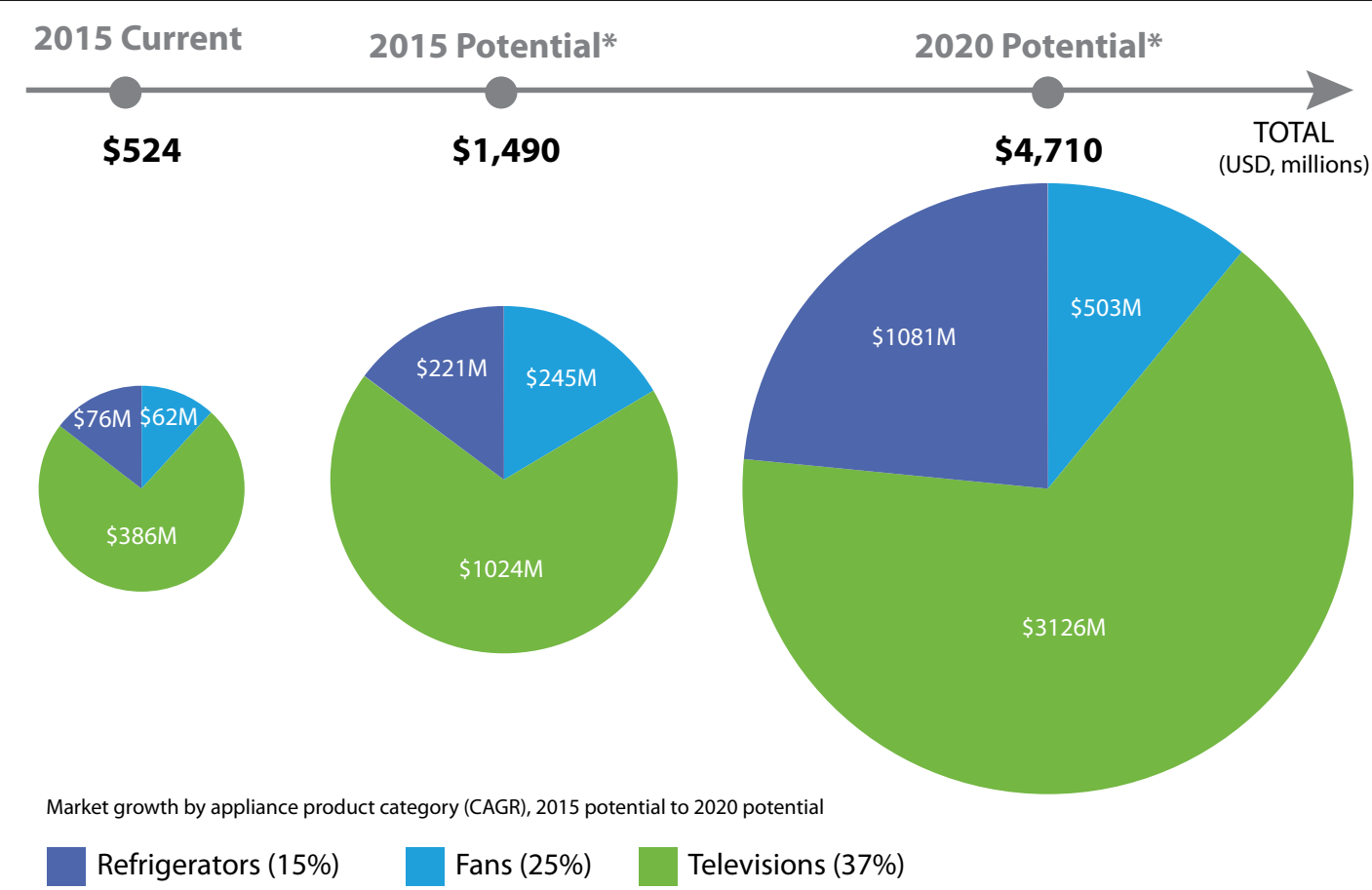

Fig. 3 Relative potential of market growth for super-efficient appliances (Global LEAP 2016)

Foundation, ${ }^{11}$ the Swedish development agency Sida, ${ }^{12}$ GIZ's Energizing Development (EnDev), ${ }^{13}$ Good Energies Foundation, ${ }^{14}$ and DOEN Foundation ${ }^{15}$ make up the Coalition's Donor Roundtable.

The Coalition's work collectively spans 19 off- and weak-grid appropriate technologies in 44 countries-a map of the Coalition donor members' current activity is shown in Fig. 4. In particular, there is significant interest from participating donors in off-grid refrigeration, as refrigerators and advanced refrigeration (e.g., cold chain technologies) are observed to be of active interest and investment across the majority of donors relative to other product categories.

Refrigeration also constitutes one of the most mature instances of donor cooperation in the sector. An example of Coalition partners ${ }^{16}$ working together to amplify

\footnotetext{
$\overline{{ }^{11} \text { Shell Foundation: www.shellfoundation.org/ }}$

${ }^{12}$ Sida: www.sida.se/English/

${ }^{13}$ EnDev: https://endev.info/content/Main_Page

${ }^{14}$ Good Energies Foundation: www.goodenergies.org/

${ }^{15}$ DOEN Foundation/ Stichting DOEN: https://www.doen.nl/aboutdoen/transitions.htm

${ }^{16}$ Power Africa, DFID, and EnDev have all contributed to the Global LEAP Awards and/or RBF program.
}

programmatic impacts on this top product category of note is through the Global LEAP Awards, which are a series of international competitions that identify the world's best, most energy-efficient off-grid appliances, ${ }^{17}$ as well as the accompanying Off-Grid Appliance Procurement Incentives Program, ${ }^{18}$ both of which will be discussed in further detail in the following sections.

\section{Market stimulation and field performance assessment for off-grid refrigerators}

\section{The Global LEAP Awards}

The Global LEAP Awards (Awards) are a series of international competitions that assess the relative quality of products and provide the off-grid market with clear, actionable signals about product performance. The Awards have been designed based on a recognition prize model and recognize off-grid appliances on the basis of a range of parameters including price, energy efficiency, quality, and off-

\footnotetext{
${ }^{17}$ Global LEAP Awards: http://globalleap.org/awards/

${ }^{18}$ Global LEAP Off-Grid Appliance Procurement Incentives Program: http://globalleap.org/incentives/
} 


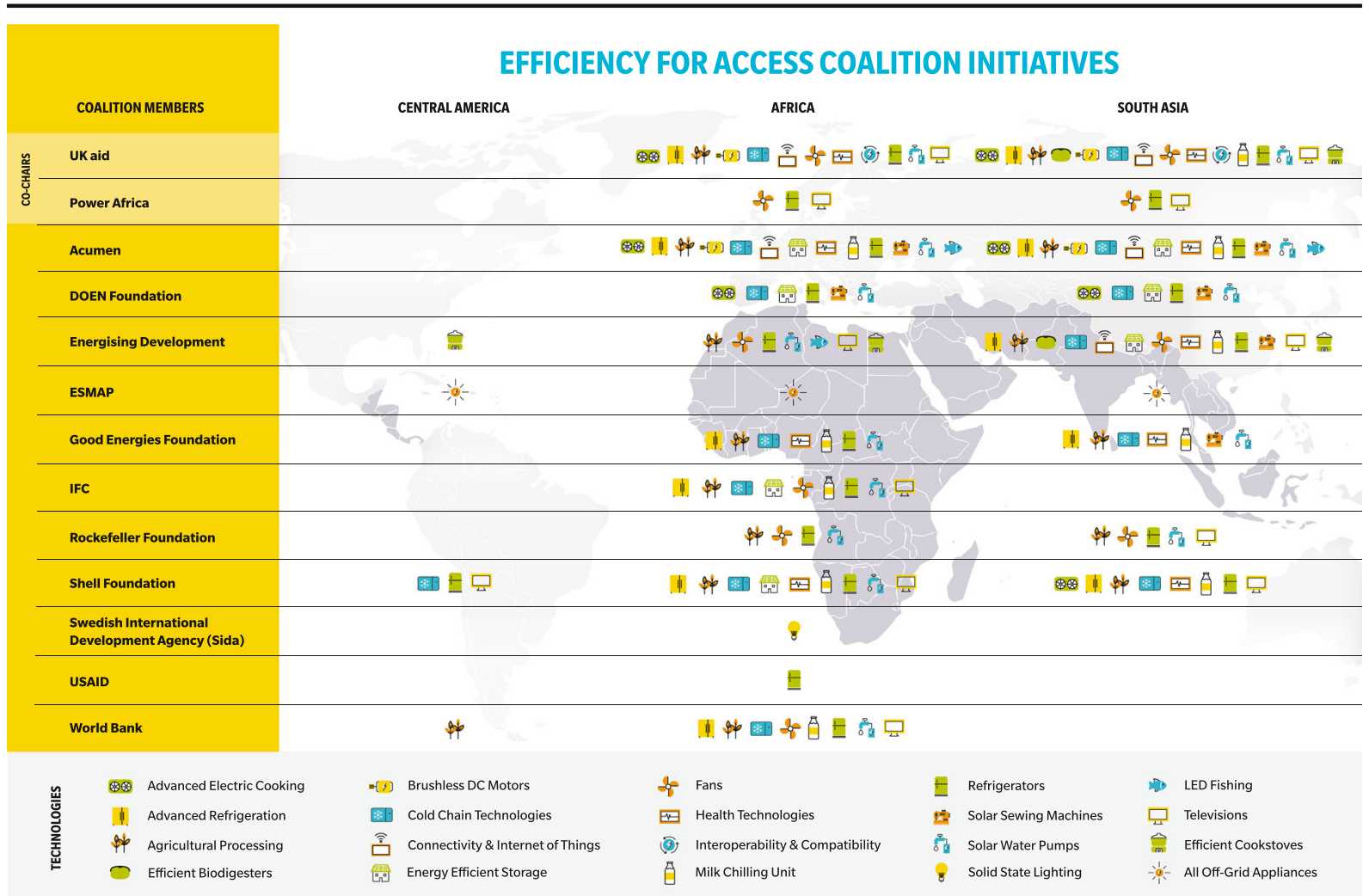

Fig. 4 Map of appliance and geographic markets of interest of efficiency for access coalition members. Last updated June 2018

grid appropriateness. The objective of the Awards is to fill a vital gap in market intelligence through the provision of laboratory-tested product data, thereby accelerating early stage-but still nascent-product markets and near-to-market technology. The inaugural Global LEAP Awards competition in 2013 included competitions for off-grid LED room lighting and off-grid TVs and has since expanded to include fans and refrigerators.

Each Awards competition round (i.e., competition year) consists of a research and planning phase before the launch, which is followed by product testing and evaluation, and ultimately an announcement of winners and dissemination of product information.

Pre-launch competition design and planning

Before launching an Awards round, a comprehensive research and planning phase is undertaken to design each competition in a way that optimizes its value to the market, especially industry. For TVs, fans, and refrigerators, this has included partnership cultivation, stakeholder consultation and research, test method development, creation of competition structure - such as evaluation criteria and rules - and communications. Developing relevant test methods, in particular, has required significant time and effort. In most cases, offgrid specific test methods do not exist or have insufficient criteria for evaluating off-grid fans, TVs, and refrigerators, requiring input from product and testing experts to develop and revise for use in the Awards.

Selection process and product evaluation

The launch of each competition officially opens a nomination window, during which off-grid appliance suppliers and distributors are solicited to nominate relevant products (TVs, fans, and refrigerators). Companies nominating products are required to fill out a basic application with company details and product specifications, as well as information about the product's relevant off-grid design. Nominated products are screened at this point for off-grid appropriateness based on factors such 
as rated power requirements and costs. Selected products are then sampled from companies' warehouses and shipped to an accredited lab for testing. All products are tested for their energy performance, quality, and reliability and evaluated by a panel of off-grid market experts. ${ }^{19}$ Global LEAP identifies Winner and Finalist products through a combination of this expert evaluation and energy- and cost-based quantitative assessments, such as lifetime cost of product.

\section{Impact and applications}

Since the inaugural competition, two more rounds of the Global LEAP Awards have been run, following signals that the off-grid appliance market emerged as a critical piece of the larger global off-grid clean energy market. In 2015 (the second round), the Awards expanded to include $\mathrm{TV}^{20}$ and $\mathrm{fan}^{21}$ competitions, and in 2017 (the third round), $\mathrm{TV}^{22}$ fan, ${ }^{23}$ and refrigerator ${ }^{24}$ competitions. The 2015 Awards received 53 product nominations, of which 26 models from 11 companies were identified as quality, off-grid appropriate products and included in the published Global LEAP Buyer's Guide. $^{25}$ The 2017 Awards received 128 product nominations, of which 49 models from 20 companies were identified as quality, off-grid appropriate products and included in the published Global LEAP Buyer's Guides ${ }^{26} \cdot{ }^{27}$

\footnotetext{
${ }^{19}$ For further details on the test methods, as well as a discussion of preliminary results and observed trends, please see the paper titled "Off-Grid Appliance Data Trends: Results and Lessons Learned from Product Testing" also available in this journal issue.

202015 Global LEAP Awards-TVs: http://globalleap.org/2015-2016-tv 212015 Global LEAP Awards-Fans: http://globalleap.org/2015-2016-fans 222017 Global LEAP Awards-TVs: http://globalleap.org/2017-buyersguide-tvs

${ }_{23}^{2} 2017$ Global LEAP Awards-Fans: http://globalleap.org/2017buyers-guide-fans

242017 Global LEAP Awards-Refrigerators: http://globalleap. org/2017-buyers-guide-for-refrigerators

${ }^{25} 2015$ Global LEAP Buyer's Guide (fans and TVs): https://static1. squarespace.com/static/56ba427f9f726695ab77ec09/t/5877ebf8e4 f c b $571 \mathrm{~d} 5$ a a a $37 \mathrm{~d} / 1484254208177 / 2016$ +Global+LEAP+Awards+Buyer\%27s+Guide+\%28May+2016\%29. pdf

${ }^{26} 2017$ Global LEAP Buyer's Guide (fans and TVs): https://static1. squarespace.com/static/56ba427f9f726695ab77ec09/t/5995dee237 c5813bc87af992/1502994152664/2017-Global-LEAP-Buyer\%27sGuide\%2D\%2DTVs-and-Fans-\%28August-2017\%29.pdf

272017 Global LEAP Buyer's Guide (refrigerators): https://static1. squarespace.com/static/56ba427f9f726695ab77ec09/t/5a969f4124 a694da85ab9282/1519820612724/2017-Global-LEAP-BuyersGuide-Refrigerators-January-2018.pdf
}

In the aftermath of the inaugural 2013-2014 Global LEAP Awards, it was recognized that severe cash-flow constraints, perceived risk (both financial and technical), and a prevailing lack of sophistication with respect to appliance business lines on the part of off-grid solar distributors continued to prevent large-scale procurement of offgrid appliances by leading SHS companies. This was observed to be the case even among important early mover companies. Companies had expressed a desire to start selling appliances. The idea of pairing the Global LEAP Awards, which vet appliances for quality and performance, with resultsbased financing (RBF) procurement incentives, which mitigate financial risk for both SHS companies and appliance manufacturers, emerged in response to this recognition.

The Global LEAP appliance procurement incentives

In 2014, CLASP, the US Department of Energy (US DOE) and the IFC, with funding from EnDev, a multi-lateral energy access initiative, launched the inaugural Global LEAP Appliance Procurement Incentives program (also known as Global LEAP+ $\mathrm{RBF}$ ). The program's overarching goal is to catalyze the global market for high-quality, superefficient off-grid appliances by demonstrating its viability to essential market and value chain stakeholders. In doing so, the program attempts to address many of the barriers currently inhibiting the growth of the off-grid appliance market listed in previous sections.

The program does this by leveraging the world's best-in-class off-grid appliances identified through the Global LEAP Awards competitions and offering financial incentives (i.e., subsidies) to offgrid energy companies in key markets to procure and sell Global LEAP Award winning and finalist products at meaningful scale. These two core activities in turn drive the following activities and impacts, all of which are essential to scaling the nascent off-grid appliance market:

- Generate critical market intelligence by collecting and disseminating data on product performance, commercial trends, consumer feedback, and market characteristics, and building awareness of key off- 
grid national and regional markets, enabling smarter, more targeted market action;

- Highlight the off-grid appliance market opportunity to appliance manufacturers and product developers who have not yet explored this rapidly emerging market, thereby encouraging further market entry;

- Demonstrate the "bankability" of the off-grid appliance market to investors and commercial lenders;

- Support policymaker efforts to develop new policy models that enable and encourage market growth, such as off-grid appliance standards and import tariff and tax reforms;

- Connect and facilitate relationships between market stakeholders-including appliance manufacturers, off-grid energy companies, and financiers - to enable smoother market functioning.

Winner and Finalist products of a given Global LEAP Awards round are eligible to participate in the matching Global LEAP Appliance Procurement Incentives program. ${ }^{28}$ The incentives are available to appliance manufacturers and off-grid solar companies that partner with each other to distribute commercially viable quantities of Global LEAP Award Winner and Finalist products in target geographies.

The incentives are designed to reduce risk across the off-grid appliance supply chain by (1) lowering the cost of best-in-class off-grid appliances for early mover off-grid solar companies and (2) providing a ready customer base for appliance manufacturers that invest in the production of high-quality off-grid appliances.

The second round of the procurement incentive window for eligible Global LEAP TVs and fans officially opened on October 16, 2017, and the volume of incentive claims submitted within the first 72 hours exceeded expectations. By the end of the first week, 27 unique incentive claims were submitted, which together accounted for 60,405 TV products and 225,825 fan products. The aggregate value of these claims exceeded the available pot of incentives. Due to this large response, CLASP closed the incentive window on October 20, 2017-5 days after it opened. To date, the procurement incentives program is supporting the

\footnotetext{
$\overline{{ }^{28} \text { Global LEAP }}$ Off-Grid Appliance Procurement Incentives program: http:/globalleap.org/incentives/
}

sale of over 230,000 highly efficient TVs, fans, and refrigerators across Kenya, Uganda, Tanzania, Rwanda, and Bangladesh.

The Global LEAP off-grid refrigerator competition and test method overview

\section{Off-grid refrigeration: opportunities and challenges}

The 2016-2017 Global LEAP Awards Off-Grid Refrigerator Competition ${ }^{29}$ was the first competition to identify and promote the world's best-inclass off-grid refrigerators. The competition was focused on off-grid refrigerators designed for household or small retail applications and open to commercially available and late-stage prototype products. $^{30}$

Designing a Global LEAP competition for refrigerators presented a unique challenge, as they are one of the most challenging off-grid appliances to design and develop to be both energy-efficient and cost-effective. The off-grid markets for technologies from previous competitions - LED lights, fans, and TVs - are relatively mature. These markets are reaching commoditization as new players continue to enter the market with innovations in technology and/or cost. For example, the Global Off-Grid Lighting Association $\left(\right.$ GOGLA $^{31}$ ) estimates that over 7 million solar lanterns and multi-light systems were sold in 2017 (GOGLA, 2017) and that the pay-as-you-go (PAYG) off-grid solar energy provider

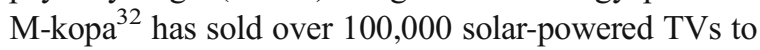
customers in East Africa. ${ }^{33}$

The refrigeration competition also presented an opportunity to make improvements in a technology that has clear socioeconomic impacts. Refrigeration provides singular benefits spanning health and productivity and significantly reduces the domestic burden on women and children, who are usually responsible for food gathering and preparation. Outside of home use, refrigeration is indispensable in hospitals and clinics-specifically for vaccine

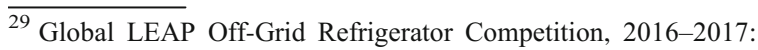
http://globalleap.org/refrigerators/

${ }^{30}$ More information can be found in Competition's terms and conditions: http://globalleap.org/s/Global-LEAP-Awards-2016-17-OffGrid-Refrigerator-Competition-Overview-20-Sep-16.pdf

${ }^{31}$ GOGLA: www.gogla.org

${ }^{32}$ M-Kopa Solar: http://www.m-kopa.com/

${ }^{33}$ TechMoran: https://techmoran.com/m-kopa-connects-100000homes-to-paygo-solar-tv/
} 
storage - and unlocks productive potential in communities for uses spanning agriculture, small business and restaurants, beverage retailers, and more (GOGLA 2018; Jones et al. 2016).

The conventional alternative current (AC) compressor refrigerators available in emerging markets consume between 1 and $2.5 \mathrm{kWh}$ per day, whereas the typical offgrid energy system does not produce sufficient energy to power these systems (Efficiency for Access 2018). Moreover, such refrigerators are often over-sized and over-priced for the typical off-grid consumer. ${ }^{34}$

However, as demand for refrigeration grows, both in domestic and in commercial markets, new refrigerators that are designed explicitly for use with a stand-alone solar home system are emerging. These refrigerators are generally smaller and consume significantly less energy than conventional products, some as low as $0.1 \mathrm{kWh}$ per day. ${ }^{35}$

Figure 5 shows how a highly efficient and appropriately designed refrigerator can radically cut the amount of energy - and the associated capital cost-needed to power a suite of off-grid appliances. Such measures would make refrigeration accessible to a much larger portion of the offand weak-grid population.

Introduction of innovation prizes and field testing to the Awards

Companies interested in tapping into the large unmet demand for refrigeration in off-grid markets lack key technical product information and do not know which companies are selling the best products. Refrigerator manufacturers also lack the technical understanding of how products need to perform for off-grid use. Conventional test methodologies are inadequate for assessing quality and off-grid appropriateness in refrigerators. The power demanded from a suite of devices is of particular importance in an off-grid power system because it determines the sizing of the PV panels and battery, ultimately impacting price. ${ }^{36}$

\footnotetext{
${ }^{34}$ For a more in-depth overview of the off-grid refrigerator market and related efficiency trends, please see the paper titled "Off-Grid Appliance Data Trends: Results and Lessons Learned from Product Testing" also available in this journal issue.

${ }^{35}$ This represents the most efficient product nominated for the 20162017 Global LEAP Awards for Off-Grid Refrigerator Competition.

${ }^{36}$ Narayan, N., Qin, Z., et al. https://link.springer. com/content/pdf/10.1007\%2Fs12053-018-9725-6.pdf
}

To address the gaps identified above, and with support from the Department for International Development (DFID), Global LEAP developed a first-of-its-kind offgrid refrigerator test method in 2016. The Global LEAP Off-Grid Refrigerator Test Method was developed in consultation with market, product, and testing experts through a working group reviewing and commenting process. ${ }^{37}$ Leveraging the existing International Electrotechnical Commission (IEC) test methods for household refrigerators and World Health Organization (WHO) test protocol for off-grid vaccine refrigerators, ${ }^{38}$ the test method was developed and modified in order to better evaluate energy consumption and energy performance of a household refrigerator in off-grid environment.

\section{Refrigerator Technology Type and Definition}

Products eligible for the 2016-2017 Global LEAP Awards Off-Grid Refrigerator Competition and the Innovation Prize are commercially available refrigerators or refrigerator-freezer combination units - the two common types of refrigerators currently available in off-grid markets. Therefore, the baseline testing efforts primarily focused on these two types of refrigerator configurations:

- Refrigerators have one or more fresh food compartments for the storage and preservation of unfrozen food and beverages, where the average storage temperature is at $4{ }^{\circ} \mathrm{C}\left(39.2^{\circ} \mathrm{F}\right)$. Another common type of refrigerators has one or more compartments that can either be used as a refrigerator or a freezer by adjusting the thermostat control. In the context of the Global LEAP Awards, these types of products are tested as refrigerators.

- Refrigerator-freezer combination units have a combination of at least one fresh food and at least one freezer compartment, where the storage temperature is not warmer than $-18^{\circ} \mathrm{C}$.

\footnotetext{
${ }^{37}$ CLASP procured a total of 36 products online, direct from manufacturers, and through field agents in off-grid areas. Among the 36 test samples, 24 were refrigerator-freezer combination units (67\%), and 12 were refrigerators only $(33 \%)$. These products underwent testing in accredited laboratories according to the Global LEAP Off-Grid Refrigerator Test Method to evaluate their energy performance, service delivery, durability, and off-grid appropriateness. You can find the Global LEAP Off-Grid Refrigerator Test Methods here: https://bit. ly/2LwTy0u and learn more about the results in the paper titled "OffGrid Appliance Data Trends: Results and Lessons Learned from Product Testing" also available in this journal issue.

${ }^{38}$ The following international refrigerator test procedures were referenced in the preparation of the Global LEAP test method: IEC 62552:2015, WHO/PQS/E003/RF05-VP.4, and IEC 60068-2-78:2012
} 


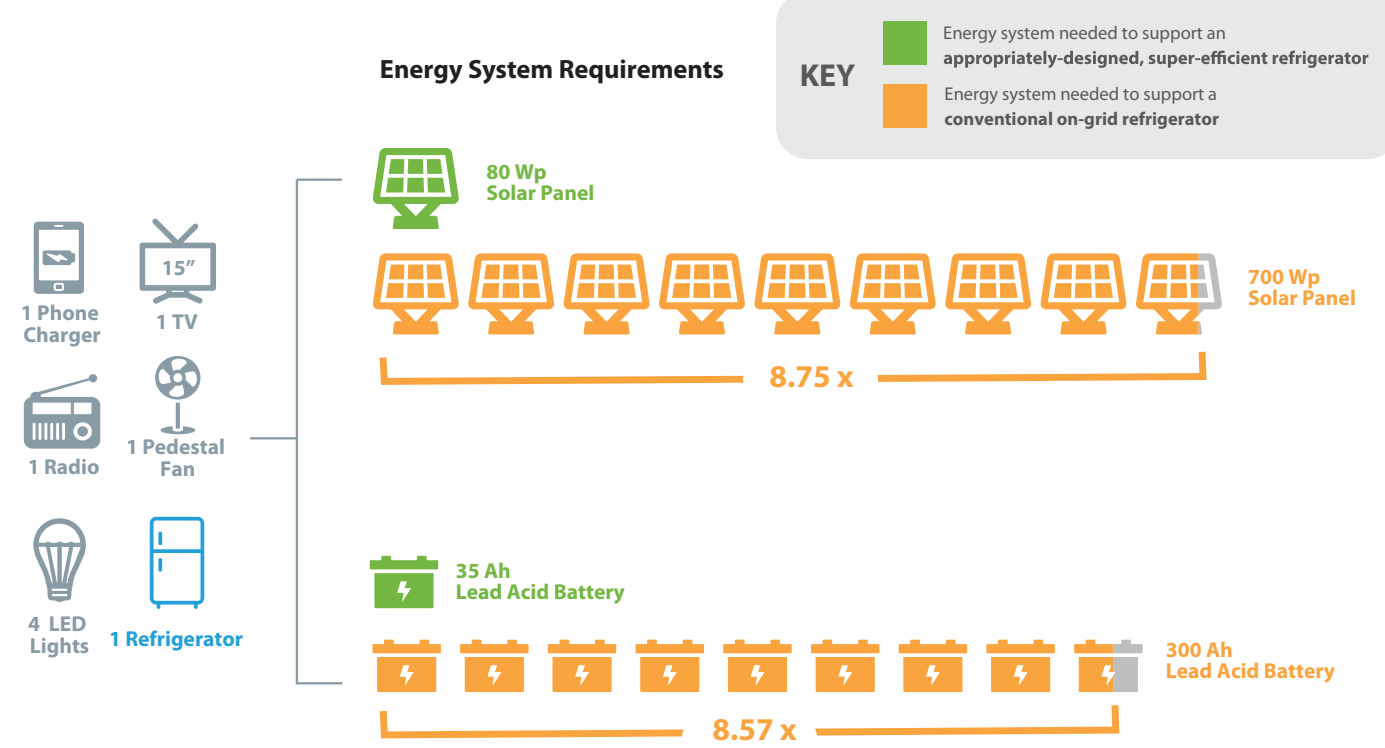

Fig. 5 Efficient and appropriately designed refrigerators dramatically reduce energy system requirements. The "appropriately designed, super-efficient refrigerator" in this scenario consumes $0.1 \mathrm{kWh}$ per day and has an $80 \mathrm{~L}$ capacity. These figures are based on rated performance data from the most efficient product nominated for the 2016-2017 Global LEAP Awards Off-Grid

\section{Baseline testing results —energy efficiency and retail price}

Since off-grid consumers are price-sensitive and energyconstrained, striking a balance between efficiency and price is often a critical business consideration for market actors in the off-grid sector (Aste et al. 2017). This
Refrigerator Competition. The "conventional on-grid refrigerator" consumes $1.75 \mathrm{kWh}$ per day and has a capacity of $691 \mathrm{~L}$. This data was obtained from the Consortium for Energy Efficiency's database and reflects typical developed world preferences and market offerings

section provides some initial insights on the dynamics between price and efficiency for refrigerators.

Figure 6 provides an overview of efficiency values and retail price of baseline products. To enable a comparison of refrigerators and refrigerator-freezers across all sizes, an efficiency metric was used for the analysis: daily energy consumed per unit size of a refrigerator,

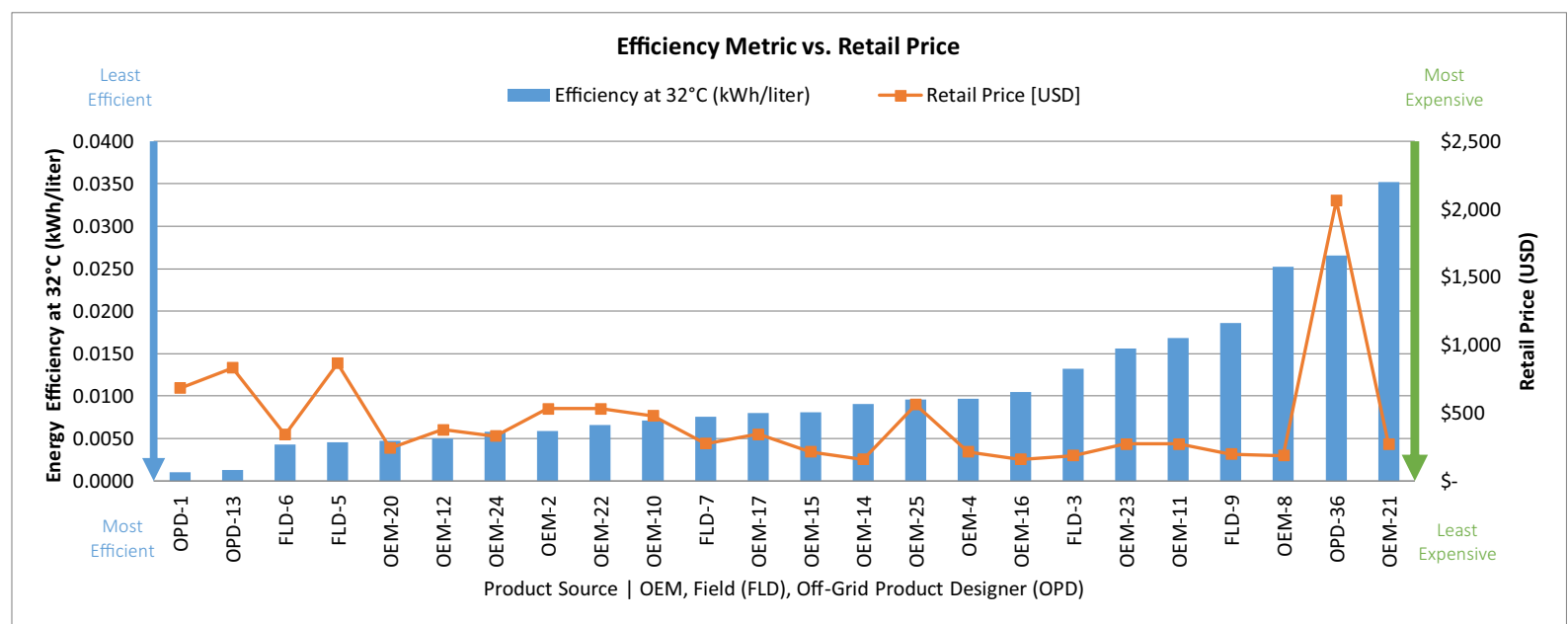

Fig. 6 Refrigerator energy efficiency vs. retail price 
defined as kilowatt hour per liter. The blue bars represent the energy efficiency values, and the orange line represents retail prices (in USD). The orange trend line shows the correlation between these two metrics.

The analysis indicated that (1) the price of products varies considerably, (2) some of the products currently available in the market are already highly energy efficient, and (3) efficiency is negatively correlated to retail price - highly energy efficient products tend to be more expensive compared to lower energy efficient products.

We conducted additional analyses to compare the trends of efficiency and price based on the following variables: refrigerator type, size, source, and power supply type, summarized in Fig. 7. Again, the orange line is the retail price in USD. The analysis indicates that (1) efficiency varies most among small refrigerator/ refrigerator-freezer combinations, (2) these refrigerator types also tend to be the least efficient products, and (3) price varies significantly among all small refrigerator types.

Introduction of innovation prizes and field testing to the Awards

The refrigeration competition introduced a unique feature to the Global LEAP Awards, since three USD $\$ 200,000$ innovation cash prizes were made available as part of the overall prize purse. All nominated products that satisfactorily completed the competition's laboratory testing process based on the Global LEAP Off-Grid Refrigerator Test Method discussed above were eligible for innovation prizes for products that demonstrate market-leading innovation in (1) overall value, (2) energy efficiency, and (3) appropriate design and user experience.

The prizes were sponsored by the U.S. Global Development $\mathrm{Lab}^{39}$ and DFID's Ideas to Impact program ${ }^{40}$ as part of their commitment to the Scaling Off-Grid Energy: A Grand Challenge for Development. ${ }^{41}$

Prizes (1) and (2) were evaluated based on laboratory test results and additional information provided by nominees. Following the evaluation of these results by an expert panel of judges, the winners of the first two innovation prizes were announced at the end of January

\footnotetext{
$\overline{39}$ Global Development Lab: www.usaid.gov/GlobalDevLab

${ }^{40}$ Ideas to Impact: www.ideastoimpact.net/

${ }^{41}$ Scaling Off-Grid: www.scalingoffgrid.org/
}

2018 in Hong Kong at the Global Off-Grid Solar Forum and Expo. ${ }^{42}$

The third innovation prize was based on field testing of eligible products to understand product performance in real-life conditions, as well as assess the impact of these products to off-grid low-income users. Prior to field-testing, Energy 4 Impact (E4I), ${ }^{43}$ CLASP's implementation partner in the field testing component of the competition, conducted a baseline study of 172 microenterprises using on-grid AC refrigerators in Uganda to better understand the productive use case for off-grid refrigerators (Grid Powered Refrigeration for Productive Use 2017).

The baseline study found a clear business case for refrigerators, with $50 \%$ of respondents in the study showing increased revenues through diversified business models and/or expanded product offerings. Despite these benefits, entrepreneurs faced challenges of quality, grid unreliability, efficiency, and service delivery. The use of inefficient refrigerators was found to be closely linked with stifling the growth of a business, or resulting in reduced profits.

For instance, one entrepreneur identified an opportunity to sell ice cream but was unable to do so because the increase in their electricity cost from running an inefficient fridge at the required temperature was prohibitive. Similarly, businesses have learned to manage the significant energy consumption of their refrigerators - and avoid high electricity bills - by running them only for intermittent periods of time instead of continuously.

Consequently, autonomy - the ability of a refrigerator to maintain the desired temperature when disconnected from the power supply - is a highly valued feature in off-grid refrigerators. Entrepreneurs are willing to pay more for this feature and are more tolerant of refrigerators with both high autonomy and higher power consumption, rather than low autonomy even with slightly lower power consumption.

In lab tests, autonomy testing measures the number of hours it takes for a product's compartment temperature to rise from 4 to $12{ }^{\circ} \mathrm{C}$ with no external power supply. The autonomy test simulates how a product would operate in the event of a battery failure or in the absence of available power supply. Figure 8 shows the

\footnotetext{
42 Official announcement of the winners of the two Innovation Prizes: https://www.energy4impact.org/news/global-leap\%E2\%80\%99s-gridrefrigerator-competition-and-innovation-prize-winners-announced

${ }^{43}$ Energy 4 Impact: https://www.energy4impact.org/
} 


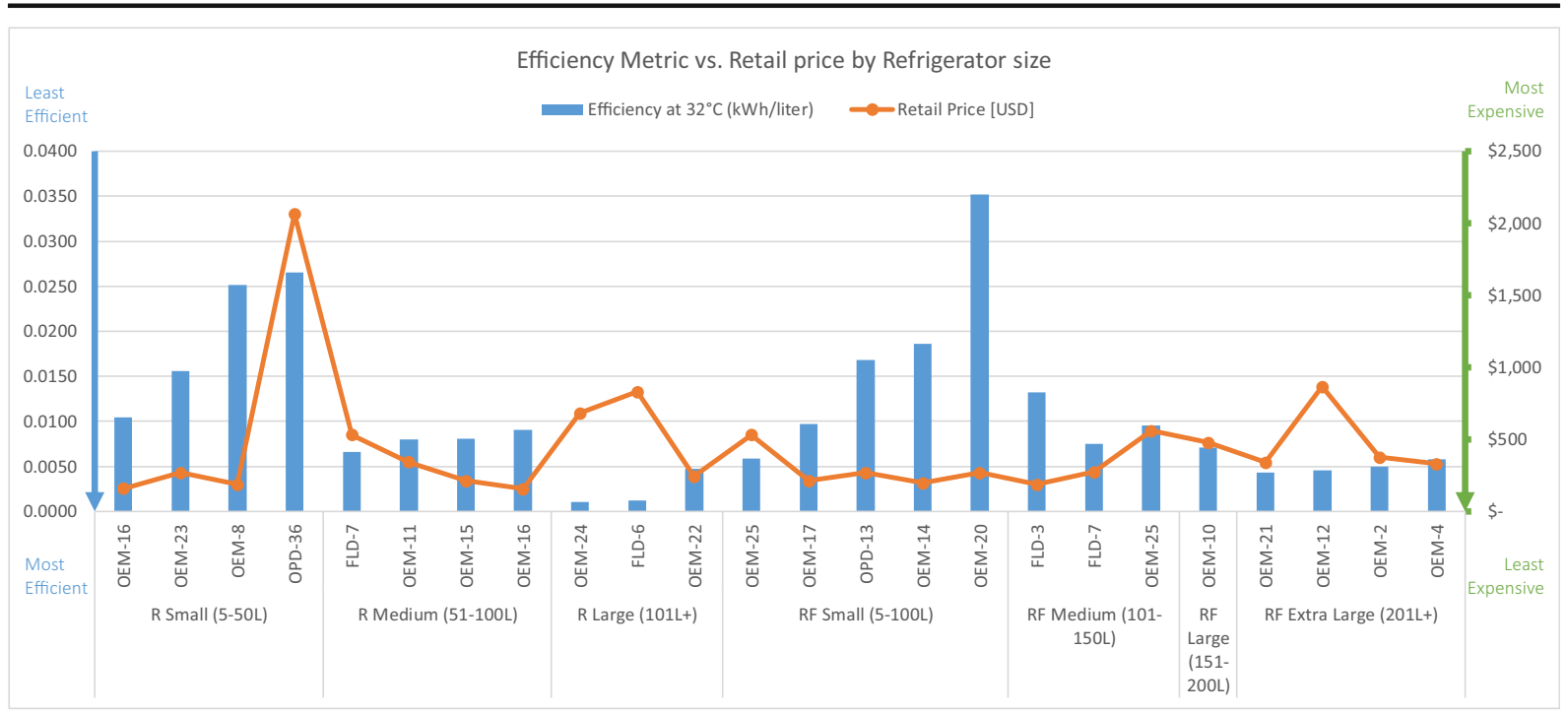

Fig. 7 Efficiency vs. retail price by refrigerator size

autonomy hours of all baseline tested products, which ranged from 0.6 to $2.6 \mathrm{~h}$. The average value of autonomy was approximately $1 \mathrm{~h}$.

The durability and serviceability of refrigerators were also found to be characteristics important to the businesses surveyed. More than a third of entrepreneurs in the study declared that they had bought their refrigerators used - and entrepreneurs reported these used refrigerators malfunction frequently and are expensive to repair or replace. This is particularly problematic because the refrigerators, even when not functioning optimally, are often critical to keeping their businesses running, and any disruption, even a short downtime for maintenance, can significantly impact their livelihoods.
Field testing methodology

\section{Overview}

Following the successful completion of the laboratory testing process, all eligible refrigerators were shipped from the testing laboratory in the Netherlands to Uganda for field testing. The aim of the field testing was to demonstrate how these products perform in "real-life" conditions, supplemented by information from end users regarding their experience using these products.

Market dynamics indicate that small retail buyers are the most likely early adopters of refrigeration technology, given both the high cost of the products and their potential

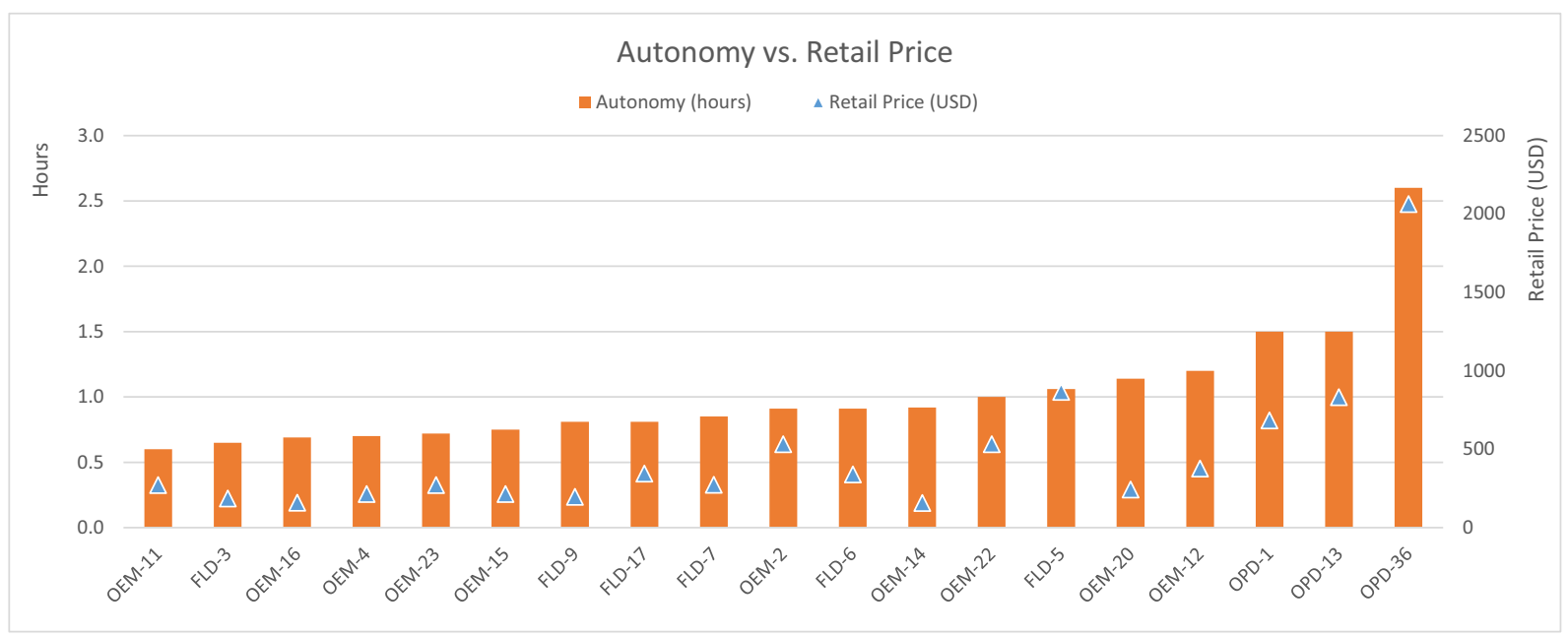

Fig. 8 Autonomy vs. retail price 
to generate new revenue sources. In line with the baseline study mentioned above, retail shops were hence selected as the best possible sites for evaluation of field performance of the refrigerators. Uganda was chosen as the location for the field testing for two primary reasons: (1) presence of a country office and team from E4I to manage the process and (2) the widespread use of off-grid solar power in Uganda, which would make it easy to identify participants.

The E4I team completed a market survey across Uganda to select field test sites based on the following characteristics:

- Business profile: Small retail shops, to the extent possible, of similar size with similar clientele and product offerings

- Climate and location: Retail shops in similar climactic zones to mitigate variability in humidity and ambient temperature and, where possible, in proximity of each other to facilitate data collection

- Familiarity with solar technology: Entrepreneurs testing the refrigerators have previous experience using solar home systems either at the test site or in their homes (e.g., use of a system for lighting and mobile phone charging).

- First time users: Entrepreneurs testing the refrigerators do not currently own or use a refrigerator. This enables assessment of a product's commercial benefits (e.g., new revenue generation) and whether products are perceived as affordable and viable by representatives of a target market segment.

\section{Data gathering}

Technical data Each refrigerator being tested was connected to a stand-alone solar energy system independent of any existing solar energy systems in operation at the test site. The program team contracted a qualified thirdparty subcontractor to size and design the systems based on the performance characteristics and energy supply requirements of the products to be tested (i.e., power rating, AC/DC power requirements) as identified previously in the test lab reports. All installations were conducted by a qualified solar technician.

Remote monitors were installed in the refrigerators to collect real-time energy consumption data spanning: (1) instantaneous power consumption, (2) accumulated energy consumption, and (3) daily power available to the product from the solar home system/battery.
The original goal of the field testing process was to collect detailed product performance data in addition to energy consumption data. Unfortunately, due to a range of technical issues with the remote meters originally sourced for the testing process, the following data was not collected for the entire duration of the field test and hence omitted from the evaluation: (1) internal compartment temperature, (2) ambient temperature, and (3) relative humidity.

Findings based on user experience The quantitative data described above was supplemented by qualitative data collected through entrepreneur interviews administered by a team of trained enumerators. The aim of these surveys was to collect more nuanced feedback on perceived technical performance, ease of use, perceived value, and overall benefits and challenges experienced by first-time users of the technology.

The physical integrity and durability of the product were also assessed by recording the physical condition of the fridge before the trial and at the time of each biweekly visit by an enumerator. This information was gathered through a visual assessment of each product and recorded on a standard form, with photos as supporting evidence.

Field testing results

Field testing of the Global LEAP Awards Winning and Finalist refrigerators officially commenced in mid-June 2018 in rural Uganda and ran until the end of August 2018. Each product's technical performance data, along with qualitative feedback from the testing entrepreneurs with regard to the utility, perceived value, and usability of the products, along with any relevant business records, were collectively analyzed. The results were summarized and presented to a panel of expert judges for evaluation. Their evaluation was used in determining the winner of the third innovation prize, which was announced in November 2018.

The following section focuses on two major findings that highlight why additional field testing is required to understand usage patterns and implications on power consumption and overall system design, as well as the importance of a feedback mechanism for manufacturers. A publication with an in-depth analysis of the results is forthcoming. ${ }^{44}$ The analysis will include a thorough

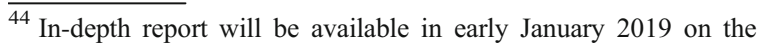
Efficiency for Access coalition website
} 
evaluation of the products lab tested performance vs. field tested performance augmented with qualitative feedback from test users.

\section{Energy consumption—laboratory vs. field performance}

The power consumption of a given refrigerator depends on the refrigerator settings, amount of refrigerant used, speed regulations of the compressor, as well as the relative humidity $(\mathrm{RH})$ and ambient temperature of the location. In lab tests, these are standardized or controlled for to enable direct comparison of refrigerator performance. One of the key tests performed in the lab is the Steady-State Operation, which measures a product's energy consumption (in kWh per day) at specified ambient temperatures and humidity levels.

Figure 9 compares the product's daily energy consumption as measured under high ambient conditions $\left(+32{ }^{\circ} \mathrm{C} / \mathrm{RH} 75 \%\right)$ in the lab compared with the product's recorded average daily energy consumption as collected by remote monitors in the field. While temperature and humidity readings are missing from the field test results, instantaneous baseline temperature and humidity readings collected at the start of the field testing exercise indicate that these products were operating at an average baseline temperature of $27^{\circ} \mathrm{C}$ and humidity of $69 \%$.
The graph indicates that most products included in the study consume significantly higher energy when operating in the field. One reason for this is that the refrigerators deployed in this study are primarily being used to cool beverages. Entrepreneurs will try to maximize the utility of their refrigerators by filling them to capacity with drinks. Throughout the day, they will take out cold drinks and re-fill the fridge with much warmer drinks to replace those being sold. This cycle of constant replacement greatly affects the power consumption of the refrigerator and the amount of time needed to cool down drinks (Harrington et al. 2018).

Figure 10 further assesses at the variance in energy consumption by refrigerator type and size. The graph shows that medium and large refrigerators in particular require much larger energy systems to operate than anticipated. This variance in energy consumption between lab testing and field observations has significant implications for energy system sizing. If $24 \mathrm{~h}$ operation is needed, these units would need to be installed with much larger PV and battery systems, which in turn means a greater total cost of product.

In addition, the majority of these businesses are run out of small shops with limited space to accommodate a large asset such as a refrigerator. While entrepreneurs can be creative in making space to accommodate a new appliance, less efficient systems that require large or multiple batteries to store energy are even more difficult

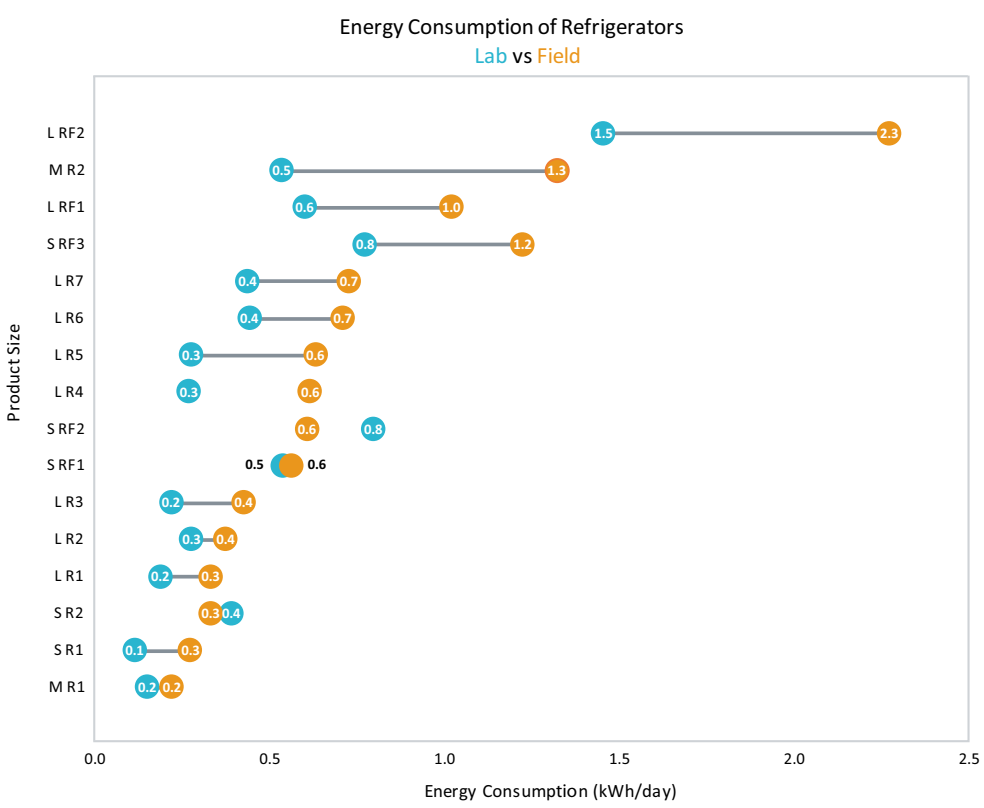

Fig. 9 Average daily energy consumption — lab vs. field 


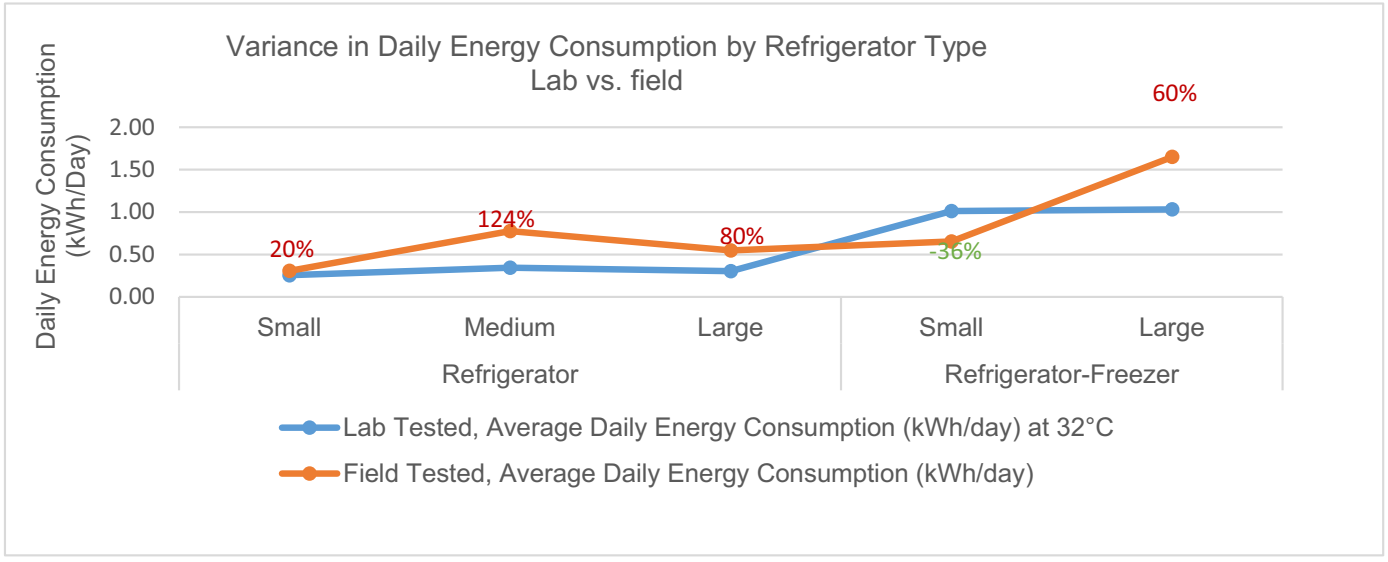

Fig. 10 Variance in daily energy consumption by refrigerator type-lab vs. field

to accommodate. This further underlines the need for revisions to lab testing methods to have a more "realworld" use representation.

\section{Ease of installation, use, and serviceability}

Unlike AC refrigerators, which for the most part can be installed without the need for any additional hardware or a specialized technician, solar DC refrigerators still require technical expertise for installation that goes beyond appropriate system sizing of the SHS required to power the refrigerator. Related to low levels of comfort with appliance technology as described above, entrepreneurs will therefore depend on a local, often uncertified, technician to assist with the installation process.

Refrigerators that are designed to be as plug-and-play as possible, with clearly labeled connectors and easy-tofollow instructions, reduce the complexity associated with installation, and require less time for the setup. This reduces the total cost of installation as well as avoiding technical issues. Removing the guesswork involved in the installation process also greatly reduces the likelihood of damage during installation. Manufacturers should not underestimate the importance of having protective mechanisms included in their models, and there should be an open line of communication between the manufacturers, the packaging and shipping teams, and the installation team to ensure everything goes smoothly with the supply chain process from start to finish.

For example, some of the compressors used in the tested refrigerators required discharging of refrigerant gases to comply with shipping requirements. However, the packaging company failed to notify the program team at CLASP that they had discharged these refrigerators of refrigerant. Consequently, the technician doing the installation was unaware that the refrigerators needed to be refilled with refrigerant before operation. As a result, once connected, these refrigerators were found to be consuming much higher power than expected and not cooling the compartments as well as they should be. In the absence of the program team at CLASP to coordinate communication between the manufacturer and the technician to identify and resolve the issue, the entrepreneurs would have abandoned these refrigerators as malfunctioning.

The entrepreneurs selected for this experiment are generally much less familiar with appliances - and solar technology more broadly - than a typical on-grid refrigerator owner. Their English literacy is generally low, which means user manuals need to be designed accordingly. Making manuals more visually descriptive and including a list of basic "dos and don'ts" could help avoid some seemingly obvious mistakes that arise due to inexperienced user error.

For example, for a refrigerator-freezer combination unit, each compartment needs to be clearly labeled to indicate which is which, and the user needs to be warned not to probe the fridge or puncture components with a sharp object. One refrigerator sample has been damaged beyond repair after an entrepreneur damaged the compressor when attempting to remove ice with a knife. Users should also be instructed not to leave the refrigerator door open or put hot items in the refrigerator compartments. Such basic instructions and tutorials would help avoid most issues that arise with appliance misuse. 


\section{Conclusions and lessons learned}

This paper highlights the need for more data and field testing to better understand how refrigerators can be designed for an off-grid customer and to maximize energy performance.

The work that has been done through Global LEAP and the Efficiency for Access Coalition to improve the appropriateness of test protocols and test data available is the most extensive effort to date to understand the energy performance and service delivery of commercially available off-grid refrigerators at an early stage of the market's development.

However, while lab tests (such as those conducted via the Global LEAP Awards) enable companies and market stakeholders to better understand product performance, the tests themselves are not sufficient in determining the real-world performance of the system. Initial observations of the variance in performance between lab and field testing point to the need for more field testing to understand user behavior and preference and how these affect overall performance of the refrigerators.

There is room for innovation among manufacturers to improve on the features that off-grid consumers are most willing to pay for. For example, in the case of autonomy, the average product on the market has an autonomy value of $1 \mathrm{~h}$-manufactures optimizing for this feature would be able to offer consumers more attractive products and would thus increase their competitiveness in the market (Efficiency for Access 2018).

Beyond technical performance, manufactures need a better understanding of the entire eco-system needed to make their products work. Efficiencies that can be gained to reduce the PV and battery storage requirements to power the system, resulting in an overall lower cost of system, are needed to make these products viable for price sensitive end-users.

Much more market intelligence is needed to collect this information with clear feedback loops to product designers and manufacturers. The Efficiency for Access Coalition recently hosted an Global Market Development Roundtable for Off-grid Refrigeration where over 40 companies and market stakeholders came together to discuss which interventions investors, donors, and others should focus on to improve the broader market ecosystem (Efficiency for Access 2018a). New research is underway to segment the market for off-grid refrigerators and assess the commercial viability for each segment. Following this, additional research will be undertaken on the segments to better understand the off-grid consumer and measure socioeconomic impacts. Improved access to market intelligence and further technological advances will bring more affordable refrigerators to nascent markets.

Funding Lawrence Berkley National Laboratory (grant number 7348019) and the UK's Department for International Development's Low-Energy Inclusive Appliances Program (grant number 300111-103).

\section{Compliance with ethical standards}

Conflict of interest The authors declare that they have no conflict of interest.

Open Access This article is distributed under the terms of the Creative Commons Attribution 4.0 International License (http:// creativecommons.org/licenses/by/4.0/), which permits unrestricted use, distribution, and reproduction in any medium, provided you give appropriate credit to the original author(s) and the source, provide a link to the Creative Commons license, and indicate if changes were made.

\section{References}

Appliance data trends 2018: insights on energy efficiency, quality, and pricing for off-grid appropriate TVs, fans, and refrigerators. (2018). Resource document. Efficiency for Access Coalition. https://efficiencyforaccess.org/publications/appliance-datatrends

Aste, N., del Pero, C., \& Leonforte, F. (2017). Active refrigeration technologies for food preservation in humanitarian contexta review. Sustainable Energy Technologies and Assessments, 22, 150-160. https://doi.org/10.1016/j.seta.2017.02.014.

Efficiency for Access. (2018a). Off- and weak-grid refrigeration: global market development roundtable workshop report. Resource document. http://www.efficiencyforaccess. org/assets/EforA-Refrigeration-Rountable-Summary-22 June2018.pdf

Energy Access Outlook 2017: From Poverty to Prosperity (2017) Resource document. International Energy Agency. https://www. iea.org/publications/freepublications/publication/WEO2017 SpecialReport_EnergyAccessOutlook.pdf. Accessed June 2018.

Global LEAP. (2016). The state of the global off-grid appliance market.. Resource document. https://s3.amazonaws. com/clasp-siteattachments/The-State-of-the-Global-OffGrid-Appliance-Market-Report.pdf. Accessed June 2018.

Global LEAP. (2017). Off-Grid Appliance Market Survey. Resource document. https://static1.squarespace. $\mathrm{com} / \mathrm{static} / 56 \mathrm{ba} 427 \mathrm{f} 9 \mathrm{f} 726695 \mathrm{ab} 77 \mathrm{ec} 09 / \mathrm{t} / 5 \mathrm{a} 29$ bec841920214496ca521/1512685258988/2017+Off- 
Grid+Appliance+Survey+Summary.pdf. Accessed June 2018.

Global Off-Grid Solar Market Report Semi-Annual Sales and Impact Data. (2017). Resource document. GOGLA. https://www.gogla.org/sites/default/files/resource docs/gogla_sales-and-impactreporth 12017_def.pdf. Accessed June 2018

GOGLA. (2018). In Powering opportunity: the economic impact of off-grid solar (Ed.), Resource document https://www. gogla.org/sites/default/files/resource_docs/gogla_powering opportunity_report.pdf.

Grid Powered Refrigeration for Productive Use. (2017). Resource Document. Energy 4 Impact. https://www.energy4impact. org/file/1946/download?token=2Li0aJN0. Accessed June 2018

Harrington, L., Aye, L., \& Fuller, R. J. (2018). Opening the door on refrigerator energy consumption: quantifying the key drivers in the home. Energy Efficiency, 11, 1519. https://doi. org/10.1007/s12053-018-9642-8.

Hirmer, S., \& Guthrie, P. (2017). The benefits of energy appliances in the off-grid energy sector based on seven off-grid initiatives in rural Uganda. Renewable and Sustainable Energy Reviews https:// w w w s i e ncedirect. com/science/article/pii/S1364032117307797. Accessed June 2018.

Jones, G., Rogers, D., Stevens, J., \& Thomas, L. (2016). Design and implementation of off-grid solar electricity supply for a rural Zambian medical facility. IEEE PES PowerAfrica, Livingstone, Zambia. https://doi.org/10.1109 /PowerAfrica.2016.7556574.

Market Baseline Performance Testing for Off-Grid \& Weak-Grid Refrigerators. (2018). Resource Document. Efficiency for Access. https://storage.googleapis.com/e4a-website-
assets/Market-Baseline-Report-Off-Grid-RefrigeratorsMay2018.pdf. Accessed June 2018.

Miller, A., et al. (2018). Chilling Prospects: Providing Sustainable Cooling for All. Resource Document. Sustainable Energy for All and Kigali Cooling Efficiency Program. https://www. seforall.org/sites/default/files/SEforALL_CoolingForAllReport_0.pdf. Accessed June 2018.

Narayan, N., Qin, Z., Popovic-Gerber, J., Diehl, J.-C., \& Al, e. (2018). Stochastic load profile construction for the multi-tier framework for household electricity access using off-grid DC appliances. Journal of Energy Efficiency https://doi. org/10.1007/s12053-018-9725-6.

Off-Grid Solar Market Trends Report. (2018). Resource document. Dalberg Advisors and Lighting Global. https://www. lightingglobal.org/2018-global-off-grid-solar-market-trendsreport/. Accessed July 2018.

Phadke, A. A., Jacobson, A., Park, W. Y., Lee, G. R., Alstone, P., \& Khare, A. (2015). Powering a home with just 25 watts of solar PV: super-efficient appliances can enable expanded off-grid energy service using small solar power systems. Ernest Orlando Lawrence Berkeley National Laboratory. https://eaei.lbl.gov/publications/powering-home-just-25 watts-solar-pv. Accessed June 2018.

World Bank. (2018). In Tracking SDG7: the energy progress report (Ed.), Resource document https://www.irena. org/publications/2018/May/Tracking-SDG7-The-EnergyProgress-Report.

Publisher's note Springer Nature remains neutral with regard to jurisdictional claims in published maps and institutional affiliations. 